\title{
Palliative Radiotherapy in the Local Management of Stage IVB Esophageal Cancer: Factors Affecting Swallowing and Survival
}

\author{
GEN SUZUKI $^{1}$, HIDEYA YAMAZAKI ${ }^{1}$, NORIHIRO AIBE ${ }^{1}$, KOJI MASUI ${ }^{1}$, KOTOHA TATEKAWA $^{1}$, \\ NAOMI SASAKI ${ }^{1}$, TAKUYA KIMOTO ${ }^{1}$, TAKESHI NISHIMURA ${ }^{1}$, AKIHIRO NAKASHIMA ${ }^{1}$, \\ TADASHI TAKENAKA ${ }^{1}$, HITOSHI FUJIWARA ${ }^{2}$, TAKESHI ISHIKAWA ${ }^{3}$ and KEI YAMADA ${ }^{1}$ \\ Departments of ${ }^{1}$ Radiology, ${ }^{2}$ Digestive Surgery, and ${ }^{3}$ Gastroenterology and Hepatology, \\ Graduate School of Medical Science, Kyoto Prefectural University of Medicine, Kyoto, Japan
}

\begin{abstract}
Aim: To clarify the role of external-beam radiotherapy in the local management of state IVB esophageal cancer. Patients and Methods: We reviewed records of 31 patients with histopathologically-proven squamous cell carcinoma who underwent radiotherapy for their primary lesion. The change in dysphagia score from before to after treatment was assessed. Nutritional support-free survival (NSFS) was also evaluated. Results: The median overall survival was 6 months. The overall rate of improvement in dysphagia score was $73 \%$ (23/31). The median NSFS was 5 months. Age at presentation $<67$ years, tumor location in the middle thoracic esophagus, and tumor length $<7 \mathrm{~cm}$ were associated with significant improvement in swallowing scores. Responders to radiotherapy had significantly longer NSFS than non-responders ( $p=0.04)$. Conclusion: Palliative radiotherapy in the local management of stage IVB esophageal cancer is an effective treatment option for dysphagia. Factors highly associated with improvement of swallowing are age, tumor location, and tumor length. Response to radiotherapy is the most important factor in improving NSFS.
\end{abstract}

Esophageal cancer is notoriously aggressive and invasive, and $20-30 \%$ of patients will have distant metastases at the time of initial diagnosis (1). The past decade has witnessed significant improvements in survival outcomes of patients with localized esophageal cancer, possibly related to the more frequent use of multimodal therapy. However, patients with metastatic

This article is freely accessible online.

Correspondence to: Gen Suzuki, MD, Department of Radiology, Kyoto Prefectural University of Medicine, 465 Kajiicho Kawaramachi Hirokoji, Kamigyo-ku, Kyoto 602-8566 Japan. Tel: +81 752515618, Fax: +81 752515840, e-mail: gensuzu@koto.kpum.ac.jp

Key Words: Palliation, esophageal cancer, radiotherapy, dysphagia, stage IVB. esophageal cancer still face a dismal prognosis. Prolonged progression-free survival (PFS) may be possible for some of these patients; however, tumor control as palliation, rather than cure of the cancer is the treatment goal for the majority, and quality of life (QOL) issues generally take precedence.

Dysphagia is a distressing symptom in advanced esophageal cancer and is the main complaint in $80 \%$ of patients (2). The main aim of treatment for patients with stage IVB esophageal cancer remains continuing oral intake without nutritional support until death. However, there is no consensus on the best approach to achieve this goal.

According to the National Comprehensive Cancer Network Clinical Practice Guidelines on Oncology ${ }^{\mathrm{TM}}$ v.1.2017 (3), palliative chemotherapy is proposed as the standard treatment in patients with metastasis, with the aims of controlling tumor growth, improving QOL, and prolonging survival.

Published rates of response to palliative chemotherapy in metastatic esophageal cancer range from 16-43\% (4-9). However, there is little evidence to suggest that chemotherapy alone improves QOL, or dysphagia $(10,11)$. There is also little evidence on the efficacy of palliative chemotherapy, particularly in squamous cell carcinoma (SCC).

External-beam radiotherapy is an effective and noninvasive modality for palliation of dysphagia. However, there have been few studies that included only patients with stage IVB esophageal cancer $(12,13)$, and no studies have assessed prognostic factors affecting nutritional support-free survival (NSFS).

The purpose of this study was to retrospectively clarify the role of radiotherapy in the local management of stage IVB esophageal SCC, focusing on improving swallowing function and NSFS.

\section{Patients and Methods}

Patients. Patients were included in this study when they met all of the following criteria: histologically-confirmed SCC of the esophagus; metastatic disease classified as stage IVB, according to 
the seventh edition of the TNM Classification of Malignant Tumor of the International Union Against Cancer (UICC) (14); primary lesion present in the thoracic esophagus; and no previous history of radiotherapy. We retrospectively investigated medical records of these patients. All patients were enrolled in this study after written informed consent had been obtained prior to treatment, in accordance with the guidelines of the Institutional Review Board of Kyoto Prefectural University of Medicine.

Treatment. External-beam radiotherapy (2.0-3.0 Gy/day) was administered once daily five times a week. The median total dose was 50 Gy (range-30-60 Gy). All patients underwent threedimensional conformal radiation therapy (3D-CRT) with computed tomographic (CT) simulation with a slice thickness of 3.0-5.0 mm. The targeted volume for irradiation basically included only the primary tumor with margins of $2-3 \mathrm{~cm}$ in the cranial-caudal direction and $1.5-2 \mathrm{~cm}$ circumferentially. Regional lymphadenopathy was not included in the target volume, except for lesions that might cause dysphagia, pain, or dyspnea. Irradiation was applied in anterior and posterior two-opposed fields or anteroposterior and oblique four-port fields. The spinal cord dose was kept at or below $40 \mathrm{~Gy}$. Treatment was delivered by linear accelerators with 6-10 MV photons. Figure 1 shows a typical case example of diagnosis and radiation field.

Chemotherapy was administered to 13 patients prior to and to 22 patients after radiotherapy. Twenty-six patients $(87 \%)$ received chemotherapy concurrently with radiotherapy, and several concurrent chemotherapy regimens were used. The most commonly used regimen ( 22 out of 26 patients) for concomitant radiotherapy was infusional 5-fluorouracil (5-FU) and weekly bolus cisplatin. The infusional 5-FU was typically provided at a dose of $700 \mathrm{mg} / \mathrm{m}^{2}$ Monday through Friday on days of radiotherapy, and bolus cisplatin was delivered once a week at a dose of $70 \mathrm{mg} / \mathrm{m}^{2}$ for the duration of radiotherapy. Other regimens used included docetaxel and S-1 alone. The usage and regimen of chemotherapy were determined by physicians according to each patient's general condition; clinical course; and organ functions, such as kidney, liver, heart, and bone marrow function. For patients who showed an objective or subjective response to treatment, additional courses of chemotherapy were repeated every 4 weeks until disease progression, development of unacceptable toxicity, or the patient's refusal to continue.

When there was a need, nutritional support was provided by fluid administration, including intravenous hyperalimentation or feeding through an enteral feeding tube.

Follow-up and assessment. The patients were assessed weekly during radiotherapy and every 4 weeks thereafter. At each visit, the patient underwent physical examination, including weight and performance status, dysphagia score, and toxicity score. Dysphagia was scored according to the system of Mellow and Pinkas as 0: able to swallow normal diet, 1: able to swallow some solid foods, 2: able to swallow any semi-solid foods, 3: able to swallow liquids only, and 4: unable to swallow anything/total dysphagia (15). Improvement of dysphagia was defined as a decrease of at least 1 point in the dysphagia score.

Toxicities were graded according to the Common Terminology Criteria for Adverse Events, version 4.0 (CTCAE) (16). Most patients who were transferred to other facilities developed disease progression and were shifted to the best supportive care. We
Table I. Patient characteristics.

\begin{tabular}{|c|c|}
\hline Characteristic & Value \\
\hline Median age (range), years & $67(46-87)$ \\
\hline \multicolumn{2}{|l|}{ Gender, $\mathrm{n}$} \\
\hline Male & 25 \\
\hline Female & 6 \\
\hline \multicolumn{2}{|l|}{ Performance status, $\mathrm{n}$} \\
\hline 0 & 20 \\
\hline 1 & 8 \\
\hline 2 & 3 \\
\hline \multicolumn{2}{|l|}{ Main tumor location, $\mathrm{n}$} \\
\hline UT & 3 \\
\hline MT & 15 \\
\hline LT & 13 \\
\hline \multicolumn{2}{|l|}{ T Stage ${ }^{\mathrm{a}}, \mathrm{n}$} \\
\hline $\mathrm{T} 2$ & 2 \\
\hline $\mathrm{T} 3$ & 18 \\
\hline $\mathrm{T} 4$ & 11 \\
\hline Median tumor length (range), $\mathrm{cm}$ & $7(3-11)$ \\
\hline \multicolumn{2}{|l|}{ Organ of metastasis, $\mathrm{n}$} \\
\hline Extraregional lymph node & 12 \\
\hline Bone & 11 \\
\hline Lung & 10 \\
\hline Liver & 4 \\
\hline Other & 5 \\
\hline \multicolumn{2}{|l|}{ Radiation dose, Gy } \\
\hline$\geq 50$ & 22 \\
\hline$<50$ & 9 \\
\hline \multicolumn{2}{|l|}{ Neoadjuvant chemotherapy, $\mathrm{n}$} \\
\hline Yes & 13 \\
\hline No & 18 \\
\hline Median follow-up (range), months & $6(2-56)$ \\
\hline
\end{tabular}

LT, Lower thoracic esophagus; MT, middle thoracic esophagus; UT,

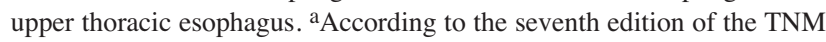
Classification of Malignant Tumor of the International Union Against Cancer (UICC) (14).

followed up their outcomes by mailing the medical facilities that accepted these patients.

Statistical analysis. All statistical analyses were performed using Stat-view 5.0 statistical software (SAS Institute, Cary, NC, USA). Overall survival (OS) was determined from the date of initiation of radiotherapy to the last day of follow-up for survivors or to the date of death. For patients who had not required nutritional support before undergoing radiotherapy, NSFS was calculated from the date of initiation of radiotherapy to the date when nutritional support was first started. The oral intake of patients who had initially required nutritional support was considered to have improved when nutritional support could be stopped. Survival data and cumulative incidences were estimated by the Kaplan-Meier method and examined for significance by the logrank test. Prognostic factors related to improvement of the dysphagia score after radiotherapy were examined by the chisquare test. Before and after dysphagia scores were compared by the Wilcoxon signed rank test. All analyses used the conventional $p<0.05$ level of significance. 

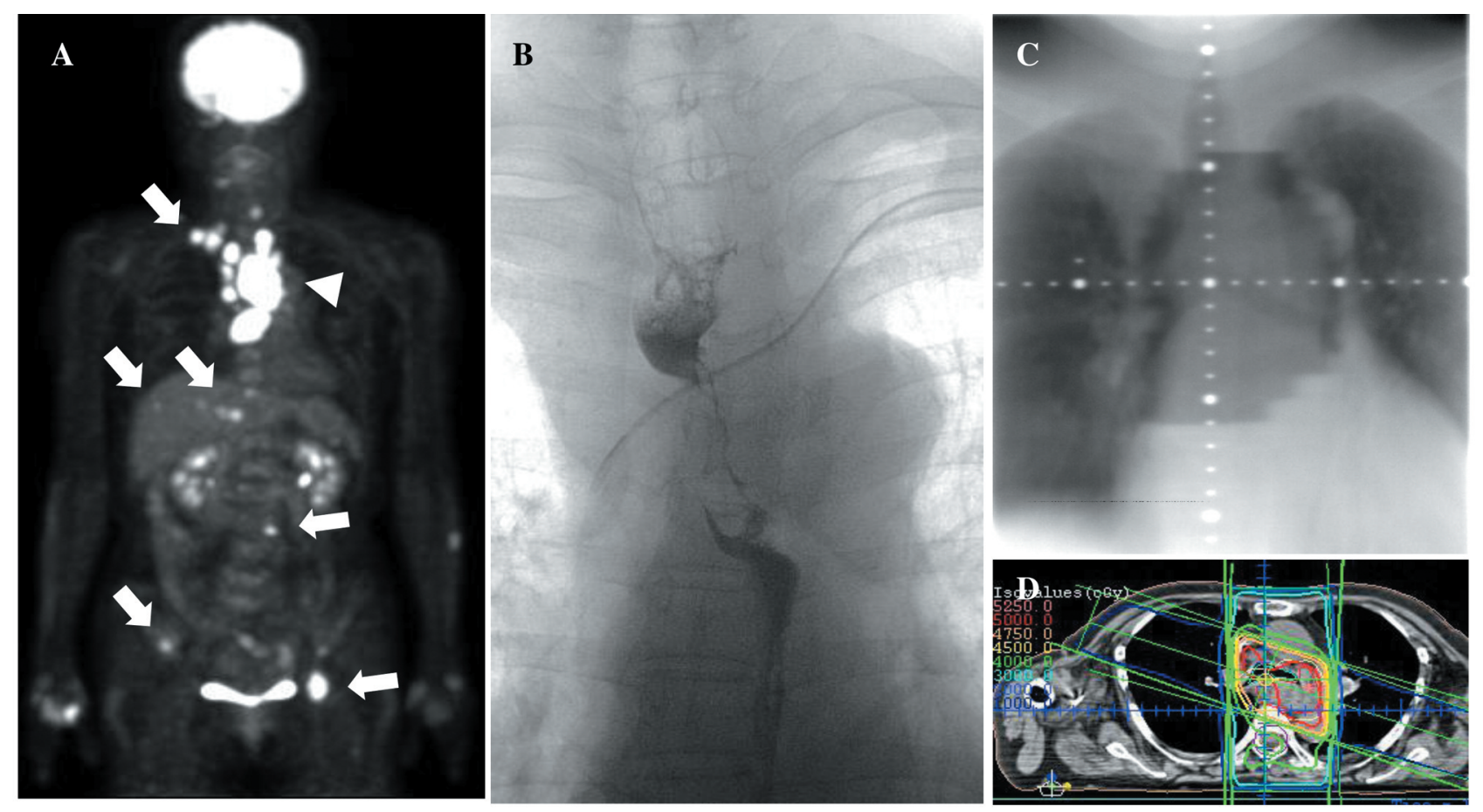

Figure 1. Case example of diagnosis and radiation field. A: Coronal image showing a 2-deoxy-2-( $\left.{ }^{18} \mathrm{~F}\right)$ fluorodeoxyglucose-avid primary tumor in the proximal esophagus (arrowhead) and several distant foci of 2-deoxy-2-( $\left.{ }^{18} \mathrm{~F}\right)$ fluorodeoxyglucose uptake in the bone, liver, and supraclavicular region (arrows). B: Barium esophagogram showing an irregular stenosis in the upper thoracic esophagus. C: LINAC-graphy (anteroposterior direction). D: Dose distribution of treatment plan. A total dose of 50 Gy was delivered in 25 fractions with anteroposterior and oblique four-port fields.

\section{Results}

Patient characteristics. Between January 2008 and October 2016, 32 patients were enrolled. One patient with supraclavicular nodal involvement without organ metastasis was excluded because in Japan, supraclavicular lymphadenopathy is considered as a regional involvement and is indicated for radical therapy; therefore, 31 patients were evaluated in total. The clinical characteristics of the study patients are presented in Table I. There were 25 men and 6 women; the male-to-female ratio was $4: 1$. The median patient age was 67 years (range $=46-87$ years). The most frequent location of the primary lesion was in the middle thoracic esophagus (48\%), and the median length of the tumor was $7 \mathrm{~cm}($ range $=3-11 \mathrm{~cm})$. Metastatic lesions were confirmed by $\mathrm{CT}$ of the neck, chest, and abdomen and 2deoxy-2- $\left({ }^{18} \mathrm{~F}\right)$ fluorodeoxyglucose positron emission tomographic scans. The most frequent sites of distant metastasis were the bone $(n=11)$, lungs $(n=10)$, and extraregional lymph nodes (e.g. axillary, para-aortic, and/or mesenteric lymphadenopathy) ( $\mathrm{n}=12)$. Most patients had a good Eastern Cooperative Oncology Group performance status $(0-1)$.
Follow-up and survival. The median follow-up was 6 months (range $=2-56$ months) from the initiation of radiotherapy. Twenty-seven out of the 31 patients had died at the time of analysis. The cause of death was disease progression in all cases. Two patients were lost to follow-up, and two had survived to the last follow-up. The median OS was 6 months, and the 6-month and 1-year OS rates were 53\% and 19\%, respectively (Figure 2). The median NSFS was 5 months, and the 6-month NSFS rate was 39\% (Figure 2).

Relationships between dysphagia score and clinical factors. All patients were assessable for degree of dysphagia. The overall rate of improvement in dysphagia score was $73 \%$ $(23 / 31)$. Eight out of nine patients $(89 \%)$ who had required nutritional support before radiotherapy were relieved from nutritional support after radiotherapy. The details of the changes in dysphagia score are shown in Table II. The Wilcoxon signed-rank test confirmed a statistically significant improvement in the dysphagia score from before to after radiotherapy ( $p=0.0001$; Figure 3 ). Seventy-one percent of all patients continued to receive various degrees of oral intake without nutritional support until death or until the last follow-up. 


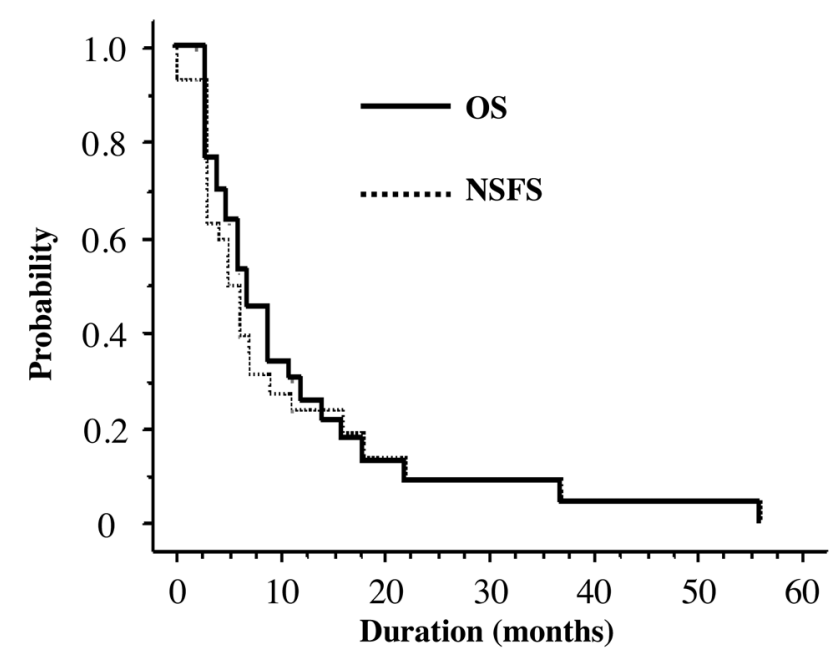

Figure 2. Overall survival (OS) and nutrition-support-free survival (NSFS) curve for patients with stage IVB esophageal cancer treated with radiotherapy.

Table II. Changes in dysphagia score after radiotherapy.

\begin{tabular}{lccccccc}
\hline \multirow{2}{*}{ Dysphagia score } & \multicolumn{5}{c}{ After radiotherapy, $\mathrm{c}$} \\
\cline { 3 - 7 } & & 0 & 1 & 2 & 3 & 4 & RR \\
\hline Initial & $1(\mathrm{n}=2)$ & 2 & 0 & 0 & 0 & 0 & $2(100 \%)$ \\
& $2(\mathrm{n}=20)$ & 3 & 10 & 6 & 1 & 0 & $13(65 \%)$ \\
& $3(\mathrm{n}=6)$ & 1 & 1 & 4 & 0 & 0 & $6(100 \%)$ \\
& $4(\mathrm{n}=3)$ & 0 & 0 & 2 & 0 & 1 & $2(67 \%)$ \\
\hline
\end{tabular}

RR, Response rate.

Table III summarizes the prognostic factors studied. Age at presentation $<67$ years, tumor location in the middle thoracic esophagus, and tumor length $<7 \mathrm{~cm}$ were significant factors related to improvement of the dysphagia score. Responders (patients with improved swallowing scores after radiotherapy) had significantly longer NSFS than nonresponders ( $p=0.04$; Figure 4$)$. The median duration of dysphagia relief and the 6-month rate of NSFS were 6 months and $47 \%$, respectively, in responders and 4 months and $21 \%$ in nonresponders. Tumor length $\geq 7 \mathrm{~cm}$ was also considered an important factor that worsened NSFS; however, the relationship was not statistically significant $(p=0.15)$ (Table III).

Toxicities. Acute toxicities of grade 3 or higher were observed in four patients (13\%), including grade 3 leukopenia in two patients, grade 3 upper respiratory

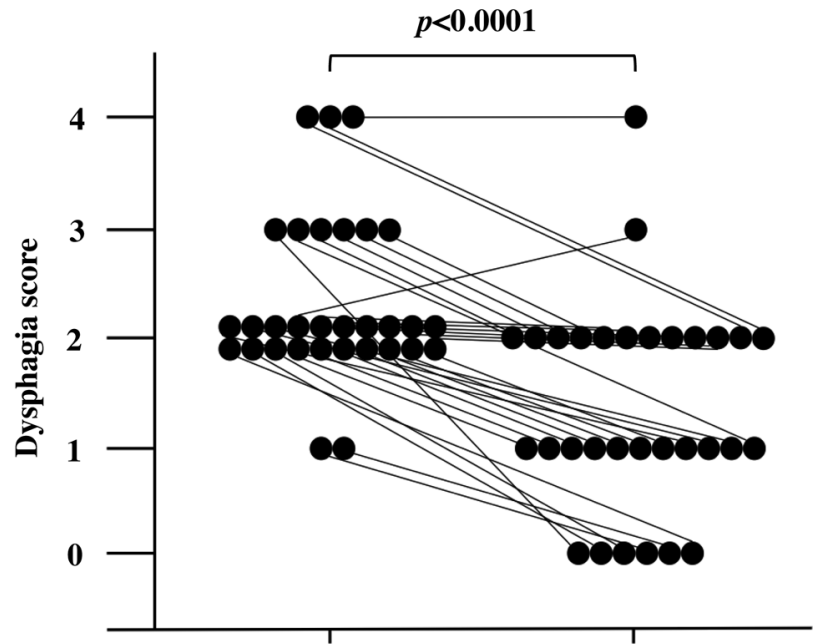

Before radiotherapy After radiotherapy

Figure 3. Effect of radiotherapy on dysphagia score.

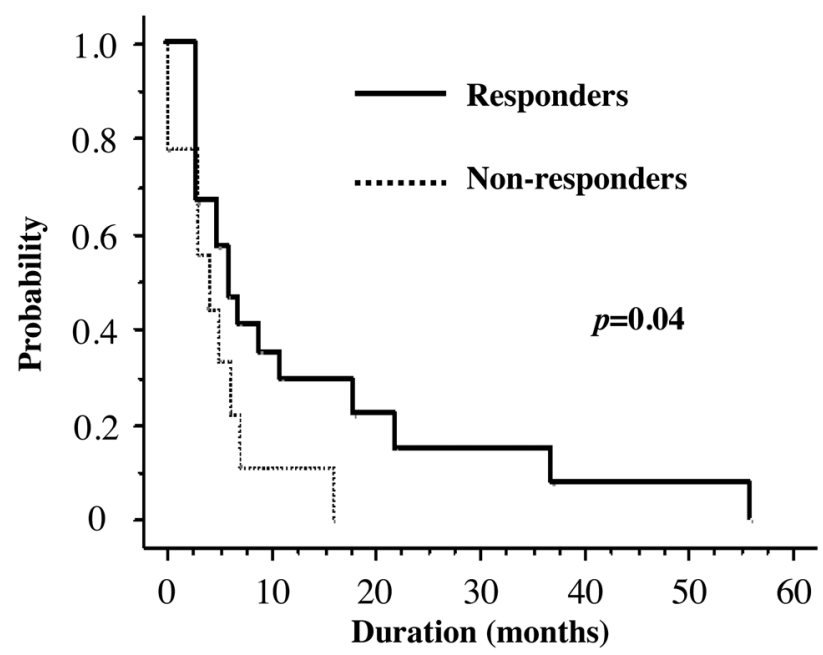

Figure 4. Nutrition-support-free survival curve after radiotherapy according to response. The difference between responders and nonresponders was significant $(p=0.04)$.

infection in one patient, and grade 4 sepsis in one patient. No patient died during radiotherapy. All patients but one completed the planned radiotherapy. With regard to late toxicity, grade 3 pneumonitis occurred in two patients (6\%). There were no grade 4 or 5 late toxicities.

Relapse of dysphagia. Nine patients (29\%) required nutritional support after radiotherapy because of reduced oral 
Table III. Analysis of potential prognostic variables and nutrition-support-free survival (NSFS).

\begin{tabular}{|c|c|c|c|c|c|}
\hline \multirow[b]{2}{*}{ Variable } & \multicolumn{2}{|c|}{ Dysphagia score after radiotherapy } & \multicolumn{3}{|c|}{ NSFS } \\
\hline & Improvement rate & $p$-Value & Median (months) & 6-Month rate & $p$-Value \\
\hline \multicolumn{6}{|l|}{ Age, years } \\
\hline$\geq 67$ & $47 \%$ & \multirow[t]{2}{*}{0.004} & 5 & $29 \%$ & \multirow[t]{2}{*}{0.41} \\
\hline$<67$ & $94 \%$ & & 6 & $49 \%$ & \\
\hline \multicolumn{6}{|l|}{ ECOG PS } \\
\hline 0 & $70 \%$ & \multirow[t]{2}{*}{0.87} & 6 & $44 \%$ & \multirow[t]{2}{*}{0.88} \\
\hline $1-2$ & $73 \%$ & & 5 & $30 \%$ & \\
\hline \multicolumn{6}{|l|}{ Location } \\
\hline MT & $93 \%$ & \multirow[t]{2}{*}{0.01} & 5 & $42 \%$ & \multirow[t]{2}{*}{0.42} \\
\hline $\mathrm{UT} / \mathrm{LT}$ & $50 \%$ & & 5 & $38 \%$ & \\
\hline \multicolumn{6}{|l|}{ Length, cm } \\
\hline$\geq 7$ & $55 \%$ & \multirow[t]{2}{*}{0.04} & 5 & $29 \%$ & \multirow[t]{2}{*}{0.15} \\
\hline$<7$ & $100 \%$ & & 7 & $53 \%$ & \\
\hline \multicolumn{6}{|l|}{ T Stage ${ }^{\mathrm{a}}$} \\
\hline $2-3$ & $70 \%$ & \multirow[t]{2}{*}{0.87} & 6 & $44 \%$ & \multirow[t]{2}{*}{0.87} \\
\hline 4 & $73 \%$ & & 4 & $30 \%$ & \\
\hline \multicolumn{6}{|l|}{ Treatment dose, Gy } \\
\hline$\geq 50$ & $73 \%$ & \multirow[t]{2}{*}{0.74} & 6 & $43 \%$ & \multirow[t]{2}{*}{0.63} \\
\hline$<50$ & $67 \%$ & & 5 & $30 \%$ & \\
\hline \multicolumn{6}{|l|}{ Initial dysphagia score } \\
\hline $1-2$ & $64 \%$ & \multirow[t]{2}{*}{0.14} & 5 & $32 \%$ & \multirow[t]{2}{*}{0.34} \\
\hline $3-4$ & $89 \%$ & & 7 & $56 \%$ & \\
\hline \multicolumn{6}{|c|}{ Dysphagia score after radiotherapy } \\
\hline $0-1$ & - & & 6 & $49 \%$ & \multirow[t]{2}{*}{0.21} \\
\hline $2-4$ & - & & 4 & $29 \%$ & \\
\hline \multicolumn{6}{|c|}{ Improvement in dysphagia score } \\
\hline Yes (responder) & - & & 6 & $47 \%$ & \multirow[t]{2}{*}{0.04} \\
\hline No (nonresponder) & - & & 4 & $21 \%$ & \\
\hline
\end{tabular}

ECOG PS, Eastern Cooperative Oncology Group performance status; LT, lower thoracic esophagus; MT, middle thoracic esophagus; UT, upper

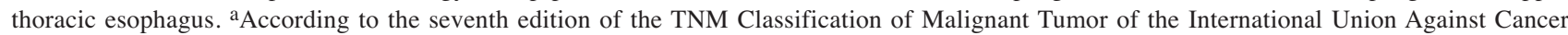
(UICC) (14).

intake of foods or liquids due to local progression. The median time to the need for nutritional support after radiotherapy was 3 months. Seven out of the nine patients underwent insertion of self-expanding metallic stents, and two underwent percutaneous endoscopic gastrostomy insertion.

\section{Discussion}

Metastatic esophageal cancer is incurable in the majority of patients. Prolonged PFS may be possible in some patients. However, control as palliation rather than cure of the cancer is the treatment goal for the majority, and QOL issues generally take precedence. One of the major goals is to improve swallowing ability in order to sustain adequate nutrition with oral intake until death.

For patients with metastatic disease, palliative chemotherapy is appropriate, and responders may have prolonged NSFS. However, the rate of response to cisplatin- based combined chemotherapy (most frequently cisplatin and 5 -FU) is only $30-40 \%$, and the response to chemotherapy typically lasts no longer than a few months, with very few exceptions $(5,7,9)$. Therefore, many patients require some form of local therapy in order to sustain locoregional control.

Historically, external beam radiotherapy has played an important role in the management of unresectable esophageal cancer, for palliation of dysphagia and maintenance of longterm locoregional disease control (17-20). However, its role in treating patients with stage IVB disease remains poorly defined (21-24).

Most initial studies primarily evaluated the role of palliative radiotherapy in patients with advanced esophageal cancer and found evidence of good local response rates ranging from $60-90 \%$, but the overall prognosis remained poor at 5 to 11 months $(12,13,25-30)$. In our study, $73 \%$ of patients had an improvement in swallowing score of 1 or more points after palliative radiotherapy, and overall, all patients had significant improvement in the swallowing 
Table IV. Published studies including the response rate of radiotherapy for esophageal cancer.

\begin{tabular}{lcccccc}
\hline Reference & Year & Patients (n) & Histology & M Stagea & Improvement in swallowing & Median survival (months) \\
\hline Coia et al. (25) & 1993 & 49 & SCC, Adeno & M0 & $91 \%$ & 8 \\
Urva and Turrisi (26) & 1995 & 27 & SCC, Adeno & M0/M1 & $59 \%$ & 6 \\
Hayter et al. (27) & 2000 & 22 & SCC, Adeno & M0/M1 & $68 \%$ & 5 \\
Harvey et al. $(28)$ & 2004 & 106 & All malignant tissue & M0/M1 & $78 \%$ & 7 \\
Burmeister et al. (29) & 2005 & 24 & SCC, Adeno & M0/M1 & $67 \%$ & 9 \\
Cho et al. (30) & 2008 & 27 & SCC & M0/M1 & $76 \%$ & 11.6 \\
Ikeda et al. (12) & 2011 & 40 & SCC & M1 & $75 \%$ & 7 \\
Akl et al. (13) & 2013 & 25 & SCC, Adeno & M1 & $72 \%$ & 6 \\
Current study & & 31 & SCC & M1 & $73 \%$ & 6 \\
\hline
\end{tabular}

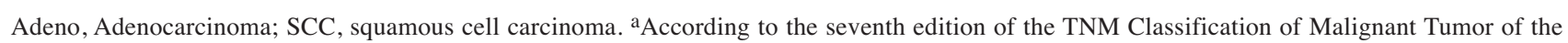
International Union Against Cancer (UICC) (14).

status $(p<0.0001$; Figure 3). The median OS time was 6 months, and the 6-month and 1-year OS rates were 53\% and $19 \%$, respectively (Figure 2). The median NSFS was 5 months, and $71 \%$ of all patients maintained their oral intake without nutritional support until death. The results of our study are comparable to those reported in other studies that used the same scoring system (Table IV).

There have been only a few studies that included only patients with stage IVB esophageal cancer $(12,13)$. A recent retrospective study by Ikeda et al. investigated 40 patients with dysphagia caused by stage IVB esophageal cancer. The treatment consisted of two courses of chemotherapy (5-FU and cisplatin) and concurrent irradiation of the primary esophageal tumor with $40 \mathrm{~Gy}$ in 20 fractions. The dysphagia score improved in $75 \%$ patients. The median NSFS was 301 days in the 20 patients who had had adequate oral intake before treatment. The median OS was 308 days, and the 1year survival rate was $45.0 \%$ (12). In a more recent prospective study by Akl et al., 25 patients with advanced and metastatic esophageal cancer were treated with concurrent 3D-CRT with 40 Gy in 22 fractions. Dysphagia was improved in $72 \%$ of patients, with an overall 5-month duration of relief from dysphagia after treatment, and the median OS was 7 months (13). These two studies also assessed the objective response of the primary tumor and reported excellent response rates.

In our study, we did not perform repeat $\mathrm{CT}$ and endoscopies routinely if there were no serious symptoms. However, in palliative studies, QOL should be the most important end-point, and assessment of the objective response may be irrelevant unless NSFS is improved. Hingorani et al. reported the outcome of patients treated with palliative local radiotherapy or chemotherapy in a wellcontrolled stage IVB disease situation after initial chemotherapy (24). They showed that both OS and time to local progression were significantly longer in patients treated with radiotherapy than in patients treated with chemotherapy alone. Previous studies have shown that external-beam radiotherapy is an effective palliative therapy in advanced esophageal cancer; however, only a few reports have evaluated prognostic factors related to swallowing improvement. Furthermore, no reports have assessed prognostic factors affecting NSFS. Coia et al. reported that patients with distal tumors had a higher frequency of initial improvement of dysphagia than those with tumors in the upper two-thirds of the thoracic esophagus (25). In our study, age at presentation $<67$ years, tumor location in the middle thoracic esophagus, and tumor length $<7 \mathrm{~cm}$ were significant factors related to the improvement of the dysphagia score. For the first two factors, reasons for this association remain unclear but they may be due to differences in tumor biology of metastatic esophageal cancer. As for tumor length, Feng et al. reported that patients with tumors $\leq 4.0 \mathrm{~cm}$ in length had better 5 -year survival than those with tumors $>4.0 \mathrm{~cm}$ in length (31). However, the clinical outcome of their trial was for non-metastatic esophageal cancer, and adequate evidence indicating an increase in NSFS is not available for those with stage IVB cancer. We found that tumor length $>7 \mathrm{~cm}$ was a clinically important factor that might improve not only the dysphagia score, but also the NSFS rate in patients with stage IVB esophageal cancer. We also found that responders had significantly longer NSFS than non-responders (Figure 4). To the best of our knowledge, this is the first report to describe prognostic factors that influence swallowing and NSFS in patients with stage IVB esophageal cancer treated with radiotherapy.

The incidence of adenocarcinoma of the esophagus has considerably increased in Western countries over the past three decades (32), whereas SCC remains the major histological type of esophageal cancer in Asian countries, including Japan. In order to represent actual Japanese clinical practice, our study included only patients with SCC. 
Chemotherapy used concomitantly with radiation is considered a good treatment option for effective tumor control. Most patients in our study were treated with concurrent chemoradiotherapy, and these patients were more likely to have an improved dysphagia score $(21 / 26,80 \%)$ than those who received radiotherapy alone $(1 / 5,20 \%)$. However, we have to accept that there could be a selection bias in our retrospective study. It is not our aim and it is beyond the scope of this study to discuss the role of chemotherapy in tumor control, which remains to be further evaluated.

Although the radiation dose was not a significant factor for the swallowing status or NSFS in this retrospective study, intensive local therapy generally might lead to better and longer dysphagia relief through tumor regression. It is important to balance the expected palliative outcome with the costs of treatment, namely, toxicities from higher irradiation and the effort of hospital visits, particularly for patients who cannot expect a complete cure.

To safely prolong survival without nutritional support, it is important to establish the appropriate doses of individual agents, as well as the irradiation dose and field. In the future, it is recommended that patients be included in prospective randomized trials to further define the appropriate use of palliative radiotherapy in the setting of stage IVB esophageal cancer with dysphagia.

\section{Conflicts of Interest}

The Authors declare that they have no competing interests in regard to this study.

\section{Funding}

This research did not receive any specific grant from funding agencies in the public, commercial, or not-for-profit sectors.

\section{References}

1 Quint LE, Hepburn LM, Francis IR, Whyte RI and Orringer MB: Incidence and distribution of distant metastases from newly diagnosed esophageal carcinoma. Cancer 76: 1120-1125, 1995.

2 Javle M, Ailawadhi S, Yang GY, Nwogu CE, Schiff MD and Nava HR: Palliation of malignant dysphagia in esophageal cancer: a literature - review. J Support Oncol 4: 365-373, 2006.

3 National Comprehensive Cancer Network. NCCN Clinical Practice Guidelines in Oncology: esophageal and esophagogastric junction cancers, v.1.2017, National Comprehensive Cancer Network. https://www.nccn.org/professionals/physician_gls/pdf/esophageal.p df (cited 2017 April 1).

4 Enzinger PC, Ilson DH and Kelsen DP: Chemotherapy in esophageal cancer. Semin Oncol 26 (Suppl 15): 12-20, 1999.

5 Hayashi K, Ando N, Watanabe H, Ide H, Nagai K, Aoyama N, Takiyama W, Ishida K, Isono K, Makuuchi H, Imamura M, Shinoda M, Ikeuchi S, Kabuto T, Yamada H and Fukuda K: Phase II evaluation of protracted infusion of cisplatin and 5fluorouracil in advanced squamous cell carcinoma of the esophagus: a Japan Esophageal Oncology Group (JEOG) Trial (JCOG9407). Jpn J Clin Oncol 31: 419-423, 2001.

6 Polee MB, Eskens FA, van der Burg ME, Splinter TA, Siersema PD, Tilanus HW, Verweij J, Stoter G and van der Gaast A: Phase II study of bi-weekly administration of paclitaxel and cisplatin in patients with advanced oesophageal cancer. Br J Cancer 86: 669-673, 2002.

7 Bleiberg H, Conroy T, Paillot B, Lacave AJ, Blijham G, Jacob JH, Bedenne L, Namer M, De Besi P, Gay F, Collette L and Sahmoud T: Randomised phase II study of cisplatin and 5fluorouracil (5-FU) versus cisplatin alone in advanced squamous cell oesophageal cancer. Eur J Cancer 33: 1216-1220, 1997.

8 Iizuka T, Kakegawa T, Ida H, Ando N, Watanabe H and Takagi I: Phase II evaluation of combined cisplatin and vindesine in advanced squamous cell carcinoma of the esophagus: Japanese Esophageal Oncology Group Trial. Jpn J Clin Oncol 21: 176$179,1991$.

9 Iizuka T, Kakegawa T, Ide H, Ando N, Watanabe H, Tanaka O, Takagi I, Isono K, Ishida K, Arimori M, Endo M and Fukushima M: Phase II evaluation of cisplatin and 5-fluorouracil in advanced squamous cell carcinoma of the esophagus: a Japanese Esophageal Oncology Group Trial. Jpn J Clin Oncol 22: 172176, 1992.

10 Homs MY, v d Gaast A, Siersema PD, Steyerberg EW and Kuipers EJ: Chemotherapy for metastatic carcinoma of the esophagus and gastro-esophageal junction. Cochrane Database Syst Rev 4: article number CD004063, 2006.

11 Levard H, Pouliquen X, Hay JM, Fingerhut A, Langlois-Zantain O, Huguier M, Lozach $\mathrm{P}$ and Testart J: 5-Fluorouracil and cisplatin as palliative treatment of advanced oesophageal squamous cell carcinoma. A multicentre randomised controlled trial. The French Associations for Surgical Research. Eur J Surg 164: 849-857, 1998.

12 Ikeda E, Kojima T, Kaneko K, Minashi K, Onozawa M, Nihei K, Fuse N, Yano T, Yoshino T, Tahara M, Doi T and Ohtsu A: Efficacy of concurrent chemoradiotherapy as a palliative treatment in stage IVB esophageal cancer patients with dysphagia. Jpn J Clin Oncol 41: 964-972, 2011.

13 Akl FM, Elsayed-Abd-Alkhalek S and Salah T: Palliative concurrent chemoradiotherapy in locally advanced and metastatic esophageal cancer patients with dysphagia. Ann Palliat Med 2: 118-123, 2013.

14 Sobin LH, Gospodarowicz MK and Wittekind Ch (eds): International Union Against Cancer (UICC). TNM Classification of Malignant Tumors, 7th edn. New York, Wiley-Blackwell, 2009.

15 Mellow MH and Pinkas H: Endoscopic laser therapy for malignancies affecting the esophagus and gastroesophageal junction. Arch Intern Med 145: 1443-1446, 1985.

16 Institute NC. Common Terminology Criteria for Adverse Events (CTCAE) version 4.0. 2009. http://evs.nci.nih.gov/ftp1/CTCAE/ CTCAE_4.03_2010-06-14_QuickReference_5x7.pdf (cited 2017 April 1).

17 Sharma V, Mahantshetty U, Dinshaw k, Deshpande R and Sharma S: Palliation of advanced/recurrent esophageal carcinoma with high dose- rate brachytherapy. Int J Radiat Oncol Biol Phys 52: 310-315, 2002.

18 Sur RK, Donde B, Levin CV and Mannell A: Fractionated high dose intraluminal brachytherapy in palliation of advanced esophageal cancer. Int J Radiat Oncol Phys 40: 447-453, 1998. 
19 Rosenblatt E, Jones G, Sur RK, Donde B, Salvajoli JV, GhoshLaskar S, Frobe A, Suleiman A, Xiao Z and Nag S: Adding external beam to intra-luminal brachytherapy improves palliation in obstructive squamous cell oesophageal cancer: A prospective multi-centre randomized trial of the International Atomic Energy Agency. Radiother Oncol 97: 488-494, 2010.

20 Sur RK, Levin CV, Donde B, Sharma V, Miszczyk and Nag S: A prospective randomized trial of HDR brachytherapy as a sole modality in palliation of advanced esophageal cancer. An IAEA study. Int J Radiat Oncol Biol Phys 53: 127-133, 2002.

21 Mariette C, Guillaume P and Triboulet J P: Therapeutic strategies in oesophageal carcinoma: role of surgery and other modalities. Lancet Oncol 8: 545-553, 2007.

22 Enzinger P C and Mayer R J: Esophageal cancer. N Engl J Med 349: 2241-2252, 2003

23 Tanaka T, Fujita H, Matono S, Nagano T, Nishimura K, Murata K, Shirouzu K, Suzuki G, Hayabuchi N and Yamada H: Outcomes of multimodality therapy for stage IVB esophageal cancer with distant organ metastasis (M1-org). Dis Esophagus 23: 646-651, 2010.

24 Hingorani M, Dixit S, Johnson M, Plested V, Alty K, Colley P, Beavis AW, Roy R and Maraveyas A: Palliative radiotherapy in the presence of well-controlled metastatic disease after initial chemotherapy may prolong survival in patients with metastatic esophageal and gastric cancer. Cancer Res Treat 47: 706-717, 2015.

25 Coia LR, Soffen EM, Schultheiss TE, Martin EE and Hanks GE: Swallowing function in patients with esophageal cancer treated with concurrent radiation and chemotherapy. Cancer 71: 281286, 1993

26 Urba SG and Turrisi AT: Split-course accelerated radiation therapy combined with carboplatin and 5-fluorouracil for palliation of metastatic or unresectable carcinoma of the esophagus. Cancer 75: 435-439, 1995.
27 Hayter CR, Huff-Winters C, Paszat L, Youssef YM, Shelley WE and Schulze K: A prospective trial of short-course radiotherapy plus chemotherapy for palliation of dysphagia from advanced esophageal cancer. Radiother Oncol 56: 329-333, 2000.

28 Harvey JA, Bessell JR, Beller E, Thomas J, Gotley DC, Burmeister BH, Walpole ET, Thomson DB, Martin I, Doyle L, Burmeister E and Smithers BM: Chemoradiation therapy is effective for the palliative treatment of malignant dysphagia. Dis Esophagus 17: 260-265, 2004.

29 Burmeister BH, Walpole ET, Burmeister EA, Thomas J, Thomson DB, Harvey JA, Mark Smithers B and Gotley DC: Feasibility of chemoradiation therapy with protracted infusion of 5-fluorouracil for esophageal cancer patients not suitable for cisplatin. Int J Clin Oncol 10: 256-261, 2005.

30 Cho SH, Shim HJ, Lee SR, Ahn JS, Yang DH, Kim YK, Nam TK, Lee JJ, Kim HJ and Chung IJ: Concurrent chemoradiotherapy with S-1 and cisplatin inadvanced esophageal cancer. Dis Esophagus 21: 697-703, 2008.

31 Feng JF, Huang Y and Zhao Q: Tumor length in elderly patients with esophageal squamous cell carcinoma: is it a prognostic factor? Ups J Med Sci 118: 145-152, 2013.

32 Devesa SS, Blot WJ and Fraumeni JF Jr.: Changing patterns in the incidence of esophageal and gastric carcinoma in the United States. Cancer 83: 2049-2053, 1998.

Received April 19, 2017

Revised April 28, 2017

Accepted May 2, 2017 